\title{
A Variational Definition for Limit and Derivative
}

\author{
Munhoz Antonio Sergio, ", Souza Filho ${ }^{2}$, Antonio Calixto ${ }^{1,2}$ \\ ${ }^{1}$ Center of Mathematics, Computation and Cognition, Federal University of ABC, Santo André, Brasil \\ ${ }^{2}$ School of Arts, Sciences and Humanity, University of São Paulo, São Paulo, Brasil \\ Email address: \\ antoniosergiomunhoz@gmail.com (M. A. Sergio), acsouzafilho@usp.br (S. Filho) \\ ${ }^{*}$ Corresponding author
}

\section{To cite this article:}

Munhoz Antonio Sergio, Souza Filho, Antonio Calixto. A Variational Definition for Limit and Derivative. American Journal of Applied Mathematics. Vol. 4, No. 3, 2016, pp. 137-141. doi: 10.11648/j.ajam.20160403.14

Received: March 12, 2016; Accepted: May 11, 2016; Published: May 22, 2016

\begin{abstract}
Using the topological notion of compacity, we present a variational definition for the concepts of limit and derivative of a function. The main result of these new definition is that they produce implementable tests to check whether a value is the limit or the derivative of a differenciable function.
\end{abstract}

Keywords: Variational, Limit, Derivative, Differenciation

\section{Introduction}

Limit is a fundamental concept in mathematics which principles date back by the time of the method of exhaustion invented by Eudoxo (408-355 aC).

The strengthening of the concept starting from Newtonian Physics at XVIII century, and a precise definition was originated as a result of the contributions of mathematicians like Cauchy, Bolzano and Weirstrass of the XIX century (see [2] for discussion about this subject and original references).

The started definition was formerly presented by Weirstrass and has been known as the $\varepsilon$ and $\delta$ definition, see [5].

Apparently, it has never been changed essentially and seems to be the only one available.

The first contribution of this paper is to bring an alternative definition for limit which, roughly speaking, can be resumed as the best local approximation for a function.

We do this in theorem 1 where we show that the value

$$
\mathrm{L}=\lim _{x \rightarrow p} f(x)
$$

is the best local approximation such that, for any value V, $\mathrm{V} \neq \mathrm{L}$,

$$
|f(x)-V|>|f(x)-L|
$$

for any $\mathrm{x}$ close to $\mathrm{p}$.

Also, without using the usual characterization of limit, but rather the so called best linear local approximation for a function, we propose to obtain an alternative definition for the derivative of a function.

By Theorems 2 and 3, we see that a differentiable function at $\mathrm{p}$ with domain and image in a finite dimensional linear space is the one whose quotient

$$
\frac{f(x)-f(p)}{|x-p|}
$$

is locally bounded at $\mathrm{p}$, and with a linear operator $\mathrm{L}$ as the best local approximation, such that:

$$
|f(x)-f(p)-L(x-p)| \leq|f(x)-f(p)-T(x-p)|
$$

for all linear operators $\mathrm{T}$ and also $\mathrm{L}=\mathrm{f}^{\prime}(\mathrm{p})$.

The insight for Theorems 2 and 3 was given as follows: take a curve and the tangent line in a point of it. Any other line is a worse local approximations for the curve.

For example, for $\mathrm{f}(\mathrm{x})=\mathrm{x}^{2}$ and $\mathrm{p}=0$ we can get that:

$$
\begin{aligned}
& \left|x^{2}\right| \leq\left|x^{2}-a x\right|, \\
& \text { for }|x|<|a| / 2 .
\end{aligned}
$$

Finally, in the last section we suggest a possible gain in using the presented definition of derivative to obtain a numerical derivative approximation.

In the next section, we work in a general setting. 


\section{Definition of Limit}

Let $\mathrm{X}$ and $\mathrm{Y}$ be metric spaces with distances denoted by I $\mid$ and $\mathrm{B}(\mathrm{r}, \mathrm{s})$ the ball with center at $\mathrm{s}$ and radius $\mathrm{r}$.

The first theorem is an alternative definition of limit. Observe that the minimum condition on the function is its image in a proper metric space, that is, a space which closed bounded sets are compact. The main innovation is the variational formulation.

Theorem 1. Let $\mathrm{X}$ be a metric space and $\mathrm{Y}$ a proper metric space. Denote by $f: X \rightarrow Y$ a function and $p$ an accumulation point of $\mathrm{X}$. The value $\mathrm{L}$ is the limit

$$
\lim _{x \rightarrow p} f(x)=L
$$

if and only if $\mathrm{f}$ is locally bounded at $\mathrm{p}$ and

$$
|\mathrm{f}(\mathrm{x})-\mathrm{L}|<|\mathrm{f}(\mathrm{x})-\mathrm{V}|,
$$

for any $V \in Y, V \neq L$, and $x \in n(p)$, where $n(p)$ is a neighborhood of $\mathrm{p}$, depending on the choice of $\mathrm{V}$.

Proof. If $\mathrm{f}$ is locally bounded, we can take a ball $\mathrm{B} \subset \mathrm{X}$ with center at $p$ and another ball $\mathrm{B}^{\prime} \subset \mathrm{Y}$ with center at 0 such that $\mathrm{f}(\mathrm{x}) \in \mathrm{B}^{\prime}$ if $\mathrm{x} \in \mathrm{B}$.

Suppose, by the way of contradiction, that $\lim _{x \rightarrow p} f(x)$ does not exist or that $\lim _{x \rightarrow p} f(x) \neq \boldsymbol{L}$.

In any case, there are $\boldsymbol{\varepsilon}_{*}>0$ and a sequence $\left(\mathrm{x}_{\mathrm{n}}\right) \subset \mathrm{X}, \mathrm{n} \geq 1$, such that $\mathrm{x}_{\mathrm{n}} \rightarrow \mathrm{p}$, if $\mathrm{n} \rightarrow+\infty$ and $\left|\mathrm{f}\left(\mathrm{x}_{\mathrm{n}}\right)-\mathrm{L}\right|>\boldsymbol{\varepsilon}_{*}$, for all $\mathrm{n} \geq 1$. Without loss of generality we assume $\quad\left(\mathrm{x}_{-} \mathrm{n}\right) \subset \mathrm{B}$.

From (1), for all $V \in Y$, we can take $n_{V}$ such that

$$
\left|\mathrm{f}\left(\mathrm{x}_{\mathrm{n}}\right)-\mathrm{V}\right|>\boldsymbol{\varepsilon}_{*}
$$

when $\mathrm{n}>\mathrm{n}_{\mathrm{V}}$, where $\mathrm{n}_{\mathrm{V}}$ depends on $\mathrm{V}$.

As $\mathrm{B}^{\prime}$ is a bounded set and $\mathrm{Y}$ is a proper metric space, there is a finite list of balls $\mathrm{B}\left(\mathrm{V}_{\mathrm{i}}, \boldsymbol{\varepsilon}_{*}\right)$

$1 \leq \mathrm{i} \leq \mathrm{N}$, which covers $\mathrm{B}^{\prime}$ :

$$
B^{\prime} \subset \bigcup_{1 \leq i \leq N} B\left(V_{i}, \varepsilon_{*}\right)
$$

From above, take $\mathrm{n}_{\mathrm{i}}$ so that

$$
\left|\mathrm{f}\left(\mathrm{x}_{\mathrm{n}}\right)-\mathrm{V}_{\mathrm{i}}\right|>\boldsymbol{\varepsilon}_{*},
$$

when $\mathrm{n}>\mathrm{n}_{\mathrm{i}}$.

Set $\boldsymbol{n}_{* *}=\max \left\{\boldsymbol{n}_{\boldsymbol{i}}, \mathbf{1} \leq \boldsymbol{i} \leq \boldsymbol{N}\right\}$. If $\mathrm{n}>\boldsymbol{n}_{* *}$, we have:

$$
\left|\mathrm{f}\left(\mathrm{x} \_\mathrm{n}\right)-\boldsymbol{V}_{\boldsymbol{i}}\right|>\boldsymbol{\varepsilon}_{*}
$$

for any $i$.

Therefore, $\mathrm{f}\left(\boldsymbol{x}_{\boldsymbol{n}}\right) \notin \mathrm{U}_{1 \leq i \leq N} \boldsymbol{B}\left(\boldsymbol{V}_{\boldsymbol{i}}, \boldsymbol{\varepsilon}_{*}\right)$ if $\mathrm{n}>\mathrm{n}_{* * *}$, which contradicts (2).

The converse is standard.

\section{Definition of Derivative}

In this section, we state an alternative definition for the concept of derivative.

Let X, Y be normed linear spaces with norm denoted by I $\mid, U \subset X$ an open set and $\mathrm{f}: \mathrm{U} \rightarrow \mathrm{Y}$, a function. The following discussion moves our investigation.

It is well known that if $\mathrm{X}$ is the real space, the derivative can be defined as

$$
\mathrm{f}^{\prime}(\mathrm{p})=\lim _{x \rightarrow p} \frac{f(x)-f(p)}{x-p} .
$$

So, by Theorem 1, $\left|\mathrm{f}(\mathrm{x})-\mathrm{f}(\mathrm{p})-\mathrm{f}^{\prime}(\mathrm{p})(\mathrm{x}-\mathrm{p})\right| \leq \mid \mathrm{f}(\mathrm{x})-$ $f(p)-V(x-p) \mid$, for any $V$ and $x \in n(p)$, where the neighborhood depends on the choice of $\mathrm{V}$.

Therefore, the derivative is the best linear approximation for a function.

A generalization of this interpretation is not so easy. We shall obtain it in two steps. First, in the next theorem, where the space of domain has finite dimension and additionally the function is continuous in a neighborhood of the point. Second, in the last theorem, the converse is obtained, but both spaces of the domain and image have finite dimension.

Theorem 2. Let $\mathrm{X}, \mathrm{Y}$ be normed spaces, $\mathrm{U} \subset \mathrm{X}$, an open set and suppose $X$ is of finite dimension. Suppose also that the function $\mathrm{f}: U \rightarrow Y$ is continuous in a neighborhood of $p \in U$. So $f$ is differentiable at $p$ and has derivative $f^{\prime}(x)=L$ only if $(\mathrm{f}(\mathrm{x})-\mathrm{f}(\mathrm{p})) /|\mathrm{x}-\mathrm{p}|$ is locally bounded at $\mathrm{p}$ and

$$
|f(x)-f(p)-L(x-p)| \leq|f(x)-f(p)-T(x-p)|,
$$

for all $T \in \mathcal{L}(X, Y)$ and $x \in n(p)$, where the neighborhood $n(p)$ depends on the choice of $T$.

Proof. Let $\mathrm{f}$ be differentiable with derivative $\mathrm{f}^{\prime}(\mathrm{p})=\mathrm{L}$. The first part of the theorem is obvious.

Assume, by the way of contradiction, that (3) is not true. For some $\boldsymbol{T}_{*}$, we can get a sequence $\left(\boldsymbol{x}_{\boldsymbol{n}}\right) \subset \mathrm{U}, \mathrm{n} \geq 1, \boldsymbol{x}_{\boldsymbol{n}} \rightarrow \mathrm{p}$, if $\mathrm{n} \rightarrow+\infty$, such that:

$$
\left|\mathrm{f}\left(\boldsymbol{x}_{\boldsymbol{n}}\right)-\mathrm{f}(\mathrm{p})-\mathrm{L}\left(\boldsymbol{x}_{\boldsymbol{n}}-\mathrm{p}\right)\right|>\left|\mathrm{f}\left(\boldsymbol{x}_{\boldsymbol{n}}\right)-\mathrm{f}(\mathrm{p})-\boldsymbol{T}_{*}\left(\boldsymbol{x}_{\boldsymbol{n}}-\mathrm{p}\right)\right|,
$$

for all $\mathrm{n} \geq 1$

Set

$$
\begin{aligned}
& \mathrm{G}(\mathrm{x})=\mathrm{f}(\mathrm{x})-\mathrm{f}(\mathrm{p})-\mathrm{L}(\mathrm{x}-\mathrm{p}), \\
& \mathrm{H}(\mathrm{x})=\mathrm{f}(\mathrm{x})-\mathrm{f}(\mathrm{p})-\boldsymbol{T}_{*}(\mathrm{x}-\mathrm{p})
\end{aligned}
$$

and

$$
\mathrm{F}(\mathrm{x})=|\mathrm{G}(\mathrm{x})|-|\mathrm{H}(\mathrm{x})| \cdot
$$

From the continuity of $x \rightarrow G(x)$ and $x \rightarrow H(x)$, the function $\mathrm{x} \rightarrow \mathrm{F}(\mathrm{x})$ is also continuous.

As $\mathrm{F}\left(\boldsymbol{x}_{\boldsymbol{n}}\right)>0, \mathrm{n} \geq 1$, and $\left(\boldsymbol{x}_{\boldsymbol{n}}\right)$ is a compact set, we have $\mathrm{F}\left(\boldsymbol{x}_{\boldsymbol{n}}\right)>\mathrm{r}, \mathrm{n} \geq 1$, for some $\mathrm{r}>0$.

Since the unit ball of $\mathrm{X}$ is compact, for any $\mathrm{n}$ there exists $\boldsymbol{y}_{\boldsymbol{n}}$ such that $\left|\boldsymbol{y}_{\boldsymbol{n}}-\mathrm{p}\right|=\left|\boldsymbol{x}_{\boldsymbol{n}}-\mathrm{p}\right|$ and

$$
\left|\frac{(T-L)\left(\left(y_{n}-\mathbf{p}\right)\right)}{\left|y_{n}-\mathbf{p}\right|}\right|=|T-L|
$$

We claim that (4) is true if we replace $\boldsymbol{x}_{\boldsymbol{n}}$ by $\boldsymbol{y}_{\boldsymbol{n}}$, for a larger $\mathrm{n}$, if necessary.

As $\boldsymbol{x}_{\boldsymbol{n}} \rightarrow \mathrm{p}$ and $\boldsymbol{y}_{\boldsymbol{n}} \rightarrow \mathrm{p}$ if $\mathrm{n} \rightarrow+\infty$, we can assert that

$$
\left|\mathrm{G}\left(\boldsymbol{x}_{\boldsymbol{n}}\right)-\mathrm{G}\left(\boldsymbol{y}_{\boldsymbol{n}}\right)\right|<\frac{\boldsymbol{r}}{2}
$$


if $\mathrm{n}>\mathrm{n}$, for some $\mathrm{n}$.

Similarly,

$$
\left.\left|\mathrm{H}\left(\boldsymbol{x}_{\boldsymbol{n}}\right)-\mathrm{H}\left(\boldsymbol{y}_{\boldsymbol{n}}\right)\right|\right) \mid<\frac{\boldsymbol{r}}{\mathbf{2}}
$$

if $n>n$.., for some n.. and there is no loss of generality in assuming $\mathrm{n} . . \mathrm{n}$.

We already know that:

$$
\left|\mathrm{G}\left(\boldsymbol{x}_{\boldsymbol{n}}\right)\right|-\left|\mathrm{H}\left(\boldsymbol{x}_{\boldsymbol{n}}\right)\right|>\mathrm{r},
$$

for all $n \geq 1$.

Combining the inequalities, we have

$$
\left|\mathrm{G}\left(\boldsymbol{y}_{\boldsymbol{n}}\right)\right|>\left|\mathrm{H}\left(\boldsymbol{y}_{\boldsymbol{n}}\right)\right|,
$$

if $\mathrm{n}>\mathrm{n}$..

Finally, take $\mathrm{s} \in(0,|\mathrm{~T} *-\mathrm{L}|)$.

From the differentiability, we can find n..., n... $\geq$ n.., such that:

$$
\left|\frac{f\left(y_{n}\right)-f(p)}{\left|y_{n}-p\right|}-L \frac{y_{n}-p}{\left|y_{n}-p\right|}\right|<\frac{s}{2}
$$

if $\mathrm{n}>\mathrm{n}$...

$$
\begin{aligned}
& \text { By (6) and (7), both } \mathrm{L} \frac{\boldsymbol{y}_{n}-\boldsymbol{p}}{\left|\boldsymbol{y}_{n}-\boldsymbol{p}\right|} \text { and } \mathrm{T} * \frac{\boldsymbol{y}_{\boldsymbol{n}}-\boldsymbol{p}}{\left|\boldsymbol{y}_{\boldsymbol{n}}-\boldsymbol{p}\right|} \text { are in the ball } \\
& \left.\mathrm{B}\left(\boldsymbol{f}\left(\boldsymbol{y}_{\boldsymbol{n}}\right)-\boldsymbol{f}(\boldsymbol{p})\right) /\left|\boldsymbol{y}_{\boldsymbol{n}}-\boldsymbol{p}\right|, \frac{\boldsymbol{s}}{\mathbf{2}}\right)
\end{aligned}
$$

if $n>n$....

Therefore:

$$
\left|\frac{f\left(y_{n}\right)-f(p)}{\left|y_{n}-p\right|}-L \frac{y_{n}-p}{\left|y_{n}-p\right|}\right|<s
$$

A contradiction of (5).

Theorem 3. Let $X, Y$ be normed linear spaces of finite dimension and $U \subset X$, an open set. The function $f: X \rightarrow Y$ is differentiable at $p$ and $\mathrm{f}^{\prime}(\mathrm{p})=\mathrm{L}$ if $(\mathrm{f}(\mathrm{x})-\mathrm{f}(\mathrm{p})) /|\mathrm{x}-\mathrm{p}|$ is locally bounded at $\mathrm{p}$ and

$$
|f(x)-f(p)-L(x-p)| \leq|f(x)-f(p)-T(x-p)|,
$$

for any $T \in \mathcal{L}(X, Y)$ and $x \in n(p)$, where the neighborhood $n(p)$ depends on the choice of $\mathrm{T}$.

Proof. Suppose, contrary to our claim, that $f$ is not differentiable at $\mathrm{p}$ or $\mathrm{f}^{\prime}(\mathrm{p}) \neq \mathrm{L}$.

Consequently, there are $\boldsymbol{\varepsilon}_{*}>0$ and a sequence $\left(\boldsymbol{x}_{\boldsymbol{n}}\right) \subset \mathrm{U}$, $\mathrm{n} \geq 1, \boldsymbol{x}_{\boldsymbol{n}} \rightarrow \mathrm{p}$, if $\mathrm{n} \rightarrow+\infty$, such that:

$$
\left\lceil\frac{\mathrm{f}\left(x_{n}\right)-\mathbf{f}(\mathbf{p})-\mathrm{L}\left(x_{n}-\mathbf{p}\right)}{\left|x_{n}-p\right|}\right\rceil>\varepsilon_{*}
$$

for all $n \geq 1$.

Since $x \rightarrow(f(x)-f(p))-L|x-p|$, then $(f(x)-f(p)) /|x-p|$ is locally bounded at $\mathrm{p}$, without loss of generality we can assume that

$$
\frac{\left|\mathbf{f}\left(x_{n}\right)-\mathbf{f}(\mathbf{p})\right|}{\left|x_{n}-\mathbf{p}\right|} \mid \leq \mathrm{R},
$$

$\mathrm{n} \geq 1$ for some $\mathrm{R}>0$.

From (8) it follows immediately that, for any $\mathrm{T} \in \mathcal{L}(\mathrm{X}, \mathrm{Y})$,

$$
\left|\frac{f\left(x_{n}\right)-f(p)}{\left|x_{n}-p\right|}-\frac{T\left(x_{n}-p\right)}{\left|x_{n}-p\right|}\right|>\varepsilon_{*}
$$

if $\mathrm{n}>\mathrm{n}_{\mathrm{T}}$, where $\mathrm{n}_{\mathrm{T}}$ depends on the choice of $\mathrm{T}$.

Next, we construct a list of operators which do not satisfy (9) obtaining a contradiction.

Obviously, $U_{\mathbf{y} \in \mathbf{B}(\mathbf{0}, \mathbf{R})} \mathbf{B}\left(\mathbf{y}, \boldsymbol{\varepsilon}_{*}\right)$ covers $\mathrm{B}(0, \mathrm{R}) \subset \mathrm{Y}$.

As $\mathrm{Y}$ is locally compact, there are $\mathrm{N}>0$ and $\mathrm{y}_{\mathrm{j}}, 1 \leq \mathrm{j} \leq \mathrm{N}$, such that:

$$
\mathrm{B}(0, \mathrm{R}) \subset \mathrm{U}_{1 \leq j \leq n} \boldsymbol{B}\left(\boldsymbol{y}_{j}, \boldsymbol{\varepsilon}_{*}\right)
$$

Denote $S=\{x \in X,|| x \mid=1\}$. For any $x \in S$ and $\boldsymbol{y}^{j}, 1<j<N$, take

$\boldsymbol{T}_{\boldsymbol{x}, \boldsymbol{y}^{j}}(\boldsymbol{x}) \in \mathcal{L}(\boldsymbol{X}, \boldsymbol{Y})$ such that $\boldsymbol{T}_{\boldsymbol{x}, \boldsymbol{y}^{j}}(\boldsymbol{x})=\boldsymbol{y}^{\boldsymbol{j}}$. Since $\xi \rightarrow \boldsymbol{T}_{x, y^{j}}(\xi)$ is continuous, we can find $\boldsymbol{\delta}_{\boldsymbol{x}, \boldsymbol{y}^{j}}>0$ with the property that $\boldsymbol{T}_{x, y^{j}}\left(\boldsymbol{B}\left(\boldsymbol{x}, \boldsymbol{\delta}_{x, y^{j}}\right)\right) \subset \boldsymbol{B}\left(\boldsymbol{y}^{j}, \boldsymbol{\varepsilon}_{*}\right)$

Let $\boldsymbol{\delta}_{\boldsymbol{x}}$ be the smallest of $\boldsymbol{\delta}_{\boldsymbol{x}, \boldsymbol{y}^{j}}, \mathbf{1} \leq \boldsymbol{j} \leq \boldsymbol{N}$.

Obviously,

$$
S \subset \bigcup_{x \in S} B\left(x, \delta_{x}\right) .
$$

From the compacity of $\mathrm{S}$, there are $\mathrm{M}>0$ and a list $x^{1}, \ldots, x^{M}$, such that

$$
S \subset \bigcup_{1 \leq i \leq M} B\left(x^{i}, \delta_{x^{i}}\right)
$$

Set $\boldsymbol{T}_{\boldsymbol{x}^{i}, \boldsymbol{y}^{\boldsymbol{j}}}$ as $\boldsymbol{T}_{\boldsymbol{i} \boldsymbol{j}}$. By (9), there exists $\boldsymbol{n}_{\boldsymbol{i} \boldsymbol{j}}$ such that

$$
\left|\frac{f\left(x_{n}\right)-f(p)}{\left|x_{n}-p\right|}-\frac{T_{i j}\left(x_{n}-p\right)}{\left|x_{n}-p\right|}\right|>\varepsilon_{*},
$$

if $\boldsymbol{n}>\boldsymbol{n}_{\boldsymbol{i} \boldsymbol{j}}$.

Setting $\boldsymbol{n}$. $\max \boldsymbol{n}_{\boldsymbol{i} \boldsymbol{j}}, \mathbf{1} \leq \boldsymbol{i} \leq \boldsymbol{M}, \mathbf{1} \leq \boldsymbol{j} \leq \boldsymbol{N}, 1$ we have

$$
\left|\frac{f\left(x_{n}\right)-f(p)}{\left|x_{n}-p\right|}-\frac{T_{i j}\left(x_{n}-p\right)}{\left|x_{n}-p\right|}\right|>\varepsilon_{*}
$$

if $\boldsymbol{n}>\boldsymbol{n}$, for all i,j.

For any $\mathrm{n} \geq 1$ and suitable $i, \mathrm{j}$, we have $\frac{x_{n}-\boldsymbol{p}}{\left|x_{n}-\boldsymbol{p}\right|} \in$ $\boldsymbol{B}\left(\boldsymbol{x}^{i}, \boldsymbol{\delta}_{x_{i}}\right)$ and $\frac{f\left(x_{n}\right)-f(p)}{\left|x_{n}-p\right|} \in \mathbf{B}\left(\mathbf{y}^{\mathbf{j}}, \boldsymbol{\varepsilon}_{*}\right)$

Hence,

$$
\left|\frac{f\left(x_{n}\right)-f(p)}{\left|x_{n}-p\right|}-\frac{T_{i j}\left(x_{n}-p\right)}{\left|x_{n}-p\right|}\right|<\varepsilon_{*},
$$

which contradicts $(10)$.

\section{Numerical Derivative}

The definition of derivative of a function as the best linear approximation provides a method to obtain its numeric value. Considering the question more closely, we see that differentiability for real functions is not enough and more regularity is necessary.

In spite of it, there is some gain. In fact, we show here that it is possible, by that definition, to get a better approximation for numeric derivative than the usual methods.

In general, numerical methods for derivative calculation 
have error estimations which depend on the machine precision.

As an example, consider the numerical derivative of a real function calculated by the finite difference method:

$$
\frac{\boldsymbol{f}(\boldsymbol{p}+\boldsymbol{h})-\boldsymbol{f}(\boldsymbol{p}-\boldsymbol{h})}{2 \boldsymbol{h}}
$$

According to [3], chapter 5 , if $\mathrm{f}$ is of class $\boldsymbol{C}^{\mathbf{3}}$, this approximation has an error of order $\varepsilon_{f}^{\frac{2}{3}}$ when the choice of $h$ is optimal, that is, when $h$ is of order $\left(\varepsilon_{f} \frac{f}{f^{\prime \prime}}\right)^{\frac{1}{3}}$. For a function $\mathrm{f}, \boldsymbol{\varepsilon}_{\boldsymbol{f}}$ is of the same order as $\boldsymbol{\varepsilon}_{\boldsymbol{m}}$ where it is the machine precision. But in general $\varepsilon_{f}$ is greater than $\boldsymbol{\varepsilon}_{\boldsymbol{m}}$.

Hence, we can choose a subset B for the last theorem. Nevertheless, relative to $h$ and $T$ where $|h| \leq r$ and $T \in B$, the numerical minimization of an expression remains impossible to be done computationally. We remove this difficulty, going to another method.

Theorem 4. Let X, Y be linear finite dimensional spaces, $\mathrm{U} \subset \mathrm{X}$ an open set and $\mathrm{f}: \mathrm{U} \rightarrow \mathrm{Y}$ of class $\boldsymbol{C}^{2}$. Take $\mathrm{p} \in \mathrm{U}$ and call $\mathrm{f}^{\prime}(\mathrm{p})=\mathrm{m}$. Setting $\boldsymbol{m}_{\mathbf{1}}$ and $\boldsymbol{m}_{\mathbf{2}}$ two approximations of $\mathrm{m}$ such $\left|\boldsymbol{m}-\boldsymbol{m}_{1}\right| \neq\left|\boldsymbol{m}-\boldsymbol{m}_{\mathbf{2}}\right|$. If

$$
\left|f(p+h)-f(p)-m_{1} h\right| \leq\left|f(p+h)-f(p)-\boldsymbol{m}_{2} h\right|,
$$

for any $\mathrm{h},|\boldsymbol{h}|=\boldsymbol{r}$, requiring only that $\mathrm{r}$ satisfies $\boldsymbol{r}<$ $\frac{\mathbf{1}}{\boldsymbol{M}}|| \boldsymbol{m}-\boldsymbol{m}_{1}|-| \boldsymbol{m}-\boldsymbol{m}_{2}||$, where $\boldsymbol{M}=\boldsymbol{m a x}_{\boldsymbol{e}}\left|\boldsymbol{f}^{\prime \prime}(\xi)\right|$ for $|\xi-\boldsymbol{p}| \leq \boldsymbol{r}$. Then

$$
\left|m-m_{1}\right|<\left|m-m_{2}\right| .
$$

Proof. Observe that the space of the norm can be obtained by the context. For instance, $\left|\left(\boldsymbol{m}-\boldsymbol{m}_{\mathbf{1}}\right) \boldsymbol{h}\right|=\left|\left(\boldsymbol{m}-\boldsymbol{m}_{\mathbf{1}}\right) \boldsymbol{h}\right|_{Y}$, $|\boldsymbol{h}|=|\boldsymbol{h}|_{X},\left|\left(\boldsymbol{m}-\boldsymbol{m}_{2}\right)\right|=\left|\left(\boldsymbol{m}-\boldsymbol{m}_{2}\right)\right|_{\mathcal{L}(X, Y)},\left|\boldsymbol{f}^{\prime \prime}(\xi)\right|=$ $\left|\boldsymbol{f}^{\prime \prime}(\xi)\right|_{\mathcal{L}\left(X^{2}, Y\right)},($ see $[1])$.

From (11):

$\left|\mathrm{f}(\mathrm{p}+\mathrm{h})-\mathrm{f}(\mathrm{p})-\mathrm{mh}+\left(\mathrm{m}-\boldsymbol{m}_{\mathbf{1}}\right) \mathrm{h}\right|<\left|\mathrm{f}(\mathrm{p}+\mathrm{h})-\mathrm{f}(\mathrm{p})-\mathrm{mh}+\left(\mathrm{m}-\boldsymbol{m}_{\mathbf{2}}\right) \mathrm{h}\right|$.

But $\mathrm{f}$ is $\boldsymbol{C}^{2}$ so:

$$
f(p+h)-f(p)-m h=\frac{f^{\prime \prime}(\xi) h^{2}}{2}
$$

where $\xi$ is between $p$ and $p+h$.

So

$$
\left|\frac{f^{\prime \prime}(\xi) h^{2}}{2}+\left(m-m_{1}\right) h\right|<\left|\frac{f^{\prime \prime}(\xi) h^{2}}{2}+\left(m-m_{2}\right) h\right|,
$$

and hence

$$
\left|\left(\boldsymbol{m}-\boldsymbol{m}_{1}\right) \frac{\boldsymbol{h}}{|\boldsymbol{h}|}\right|<\left|\left(\boldsymbol{m}-\boldsymbol{m}_{2}\right) \frac{\boldsymbol{h}}{|\boldsymbol{h}|}\right|+\left|\boldsymbol{f}^{\prime \prime}(\xi)\right||\boldsymbol{h}| .
$$

This gives that:

$$
\left|\left(\boldsymbol{m}-\boldsymbol{m}_{1}\right) \frac{\boldsymbol{h}}{|\boldsymbol{h}|}\right|<\left|\left(\boldsymbol{m}-\boldsymbol{m}_{2}\right)\right|+\left|\boldsymbol{f}^{\prime \prime}(\xi)\right||\boldsymbol{h}| .
$$

Since $\mathrm{X}$ has finite dimension, there is $\boldsymbol{h}_{*} \in\{\boldsymbol{h}|| \boldsymbol{h} \mid=\boldsymbol{r}\}$ such that

$$
\left|\left(\boldsymbol{m}-\boldsymbol{m}_{\mathbf{1}}\right)\right|=\left|\left(\boldsymbol{m}-\boldsymbol{m}_{\mathbf{1}}\right) \frac{\boldsymbol{h}_{*}}{\left|\boldsymbol{h}_{*}\right|}\right|
$$

And the last two relations give:

$$
\left|\left(\boldsymbol{m}-\boldsymbol{m}_{1}\right)\right|<\left|\left(\boldsymbol{m}-\boldsymbol{m}_{2}\right)\right|+\left|\boldsymbol{f}^{\prime \prime}(\xi)\right|\left|\boldsymbol{h}_{*}\right| .
$$

This forces that $\left|\boldsymbol{m}-\boldsymbol{m}_{\mathbf{1}}\right|>\left|\left(\boldsymbol{m}-\boldsymbol{m}_{\mathbf{2}}\right)\right|$. In fact, if the opposite was true, we would have:

$$
\left|f^{\prime \prime}(\xi)\right|\left|h_{*}\right|>||\left(m-m_{1}\right)|-|\left(m-m_{2}\right)||
$$

and so

$$
\left|h_{*}\right|>\frac{||\left(\boldsymbol{m}-\boldsymbol{m}_{1}\right)|-|\left(\boldsymbol{m}-\boldsymbol{m}_{2}\right)||}{M}
$$

that is contrary to the assumption that $\left|\boldsymbol{h}_{*}\right|=\boldsymbol{r}$.

The last proposition gives a test to decide, between $\boldsymbol{m}_{\mathbf{1}}$ and $\boldsymbol{m}_{\mathbf{2}}$, which of them is closer to the derivative $\mathrm{m}$ comparing the residues. But the criterion

$$
|h|<\frac{||\left(m-m_{1}\right)|-|\left(m-m_{2}\right)||}{M}
$$

is not practical because uses the value of the unknown $m$.

Nevertheless, using the test when the criterion is false will not produce worse results. In this case,

$$
\frac{||\left(\boldsymbol{m}-\boldsymbol{m}_{2}\right)|-|\left(\boldsymbol{m}-\boldsymbol{m}_{1}\right)||}{M} \leq|\boldsymbol{h}|
$$

So, if $\mathrm{M}$ is not so big, the difference between the errors $\left|\boldsymbol{m}-\boldsymbol{m}_{\mathbf{1}}\right|$ and $\left|\boldsymbol{m}-\boldsymbol{m}_{\mathbf{2}}\right|$ is of order $|\mathrm{h}|$.

We now consider an example to show how using this test.

Set $f(x)=x^{\wedge} 3$. By the finite difference scheme, supposing $\varepsilon_{m}$ of order $10^{-7}$ and using h of order $10^{-\frac{7}{3}}$, the error will be of order $10^{-\frac{14}{3}}$. To calculated the residues, we observe that $\mathrm{f}(1)=1.0000000, \mathrm{f}(1+\mathrm{h})=1.0000002$.

The tables 1 and 2 show firstly that the best approximation among $3.0000000,3.0000010, \ldots, 3.0000090$

is 3.0000000 . Next, the second table shows that the best approximation among

$3.0000000, \ldots, \quad 3.0000005$ is 3.0000000 . So the approximation 3.000000 has 7 correct digits.

To clarify the procedure used in the last paragraph, it may be convenient to do the following observation.

If $\boldsymbol{m}_{\mathbf{1}}$ is a better approximation for $m$ than $\boldsymbol{m}_{\mathbf{2}}$ (or $\boldsymbol{m}_{\mathbf{1}}$ is closer than $\boldsymbol{m}_{\mathbf{2}}$ to $\mathrm{m}$ ) then $\boldsymbol{m} \leq \frac{\boldsymbol{m}_{1}+\boldsymbol{m}_{2}}{\mathbf{2}}$ when $\boldsymbol{m}_{\mathbf{1}}<\boldsymbol{m}_{\mathbf{2}}$ and $\boldsymbol{m} \geq \frac{\boldsymbol{m}_{1}+\boldsymbol{m}_{2}}{\mathbf{2}}$ when $\boldsymbol{m}_{\mathbf{1}}>\boldsymbol{m}_{\mathbf{2}}$.

This gives the algorithm which we shortly describe below.

For simplicity, suppose that $\mathrm{m}=0 . \mathrm{d}_{1} 00^{*} 10^{\mathrm{f}}$ and it is known that the digit $d_{1}$ is correct. Our aim is to obtain the second and the third correct digits in the following steps.

1. Obtain the best approximation among the values $0 . \mathrm{d}_{1} \mathrm{t} 0 * 10^{\mathrm{f}}$ for $\mathrm{t}=0,1, \ldots, 9$ and set it as $\mathrm{d}$. 
2. Consider the case options:

Case $\mathrm{d}=0$. Obtain the best linear approximation among 0.d $10 \mathrm{t} * 10^{\mathrm{f}}$ for $\mathrm{t}=0,1,2,3,4,5$; set it as $\mathrm{d}_{3}$ and do $\mathrm{d}_{2}=0$.

$\bar{C}$ ase $\mathbf{1} \leq \boldsymbol{d} \leq \mathbf{8}$. Obtain the best linear approximation among the data $0 . \mathrm{d}_{-} 1(\mathrm{~d}-1) \mathrm{t}_{1} * 10^{\mathrm{f}}$ for $\mathrm{t}_{1}=5,6,7,8,9$ and among the data $0 . \mathrm{d}_{1} \overline{\mathrm{dt}}_{2} * 10^{\mathrm{f}}$ for $\mathrm{t}_{2}=0,1,2,3,4,5$. If the best approximation of the each data group are in the first one, then $\mathrm{d}_{2}=\mathrm{d}-1$ and $\$ \mathrm{~d}_{3}=\mathrm{t}_{1}$. Otherwise $\mathrm{d}_{2}=\mathrm{d}$ and $\mathrm{d}_{3}=\mathrm{t}_{2}$.

Case $\mathrm{d}=9$. Obtain the best linear approximation among data $\$ 0 . d_{1} 8 t * 10^{f}$ for $t=5,6,7,8,9$ and $\$ 0 . d_{1} 90 * 10^{f}$. If the best approximation is in the first group, set $d_{2}=8$ and $d_{3}=$ t. Otherwise, set $\mathrm{d}_{2}=9 \$$ and $\mathrm{d}_{3}=0$.

In general, calling as $\mathrm{H}$ the hyperplane equidistant from $\boldsymbol{m}_{\mathbf{1}}$ and $\boldsymbol{m}_{\mathbf{2}}$, so $\mathrm{m}$ is in the side of $\mathrm{H}$ that contains $\boldsymbol{m}_{\mathbf{1}}$.

The tables forward shows the numerical results.

Table 1. Residue calculation.

\begin{tabular}{ll}
\hline $\mathbf{m}$ & $|\mathbf{f}(\mathbf{1}+\mathbf{h}) \mathbf{f}(\mathbf{1})-\mathbf{m h}|$ \\
\hline 3.0000000 & $1.0000000 * 10^{-7}$ \\
3.0000001 & $1.0000010 * 10^{-7}$ \\
3.0000002 & $1.0000020 * 10^{-7}$ \\
3.0000003 & $1.0000030 * 10^{-7}$ \\
3.0000004 & $1.0000040 * 10^{-7}$ \\
3.0000005 & $1.0000050 * 10^{-7}$ \\
3.0000006 & $1.0000060 * 10^{-7}$ \\
\hline
\end{tabular}

Table 2. Residue calculation.

\begin{tabular}{ll}
\hline $\mathbf{m}$ & $|\mathbf{f}(\mathbf{1}+\mathbf{h}) \mathbf{f}(\mathbf{1})-\mathbf{m h}|$ \\
\hline 3.0000000 & $1.0000000 * 10^{-7}$ \\
3.0000001 & $1.0000001 * 10^{-7}$ \\
3.0000002 & $1.0000002 * 10^{-7}$ \\
3.0000003 & $1.0000003 * 10^{-7}$ \\
3.0000004 & $1.0000004 * 10^{-7}$ \\
3.0000005 & $1.0000005 * 10^{-7}$ \\
\hline
\end{tabular}

\section{Conclusion}

We dealt with the definition limit and derivative of a function, which is well known, it is a historically intricate question. Thus, we proposed alternatives definition of these concepts that have, as mainly differences of the standard ones, the fact they are implementable forms and also that such definitions drop out the $\varepsilon$ of the $\delta$ - $\varepsilon$ usual definitions.

\section{References}

[1] Dieudonne, J., Foundations of Modern Analysis, Pure and Applied Mathematics \textbf $\{10\}$, Academic Press, New York, 1960.

[2] J. V. Grabiner, J. V., Who Gave You the Epsilon? Cauchy and the Origins of Rigorous Calculus, The American Mathematica Monthly (90) (3), 185-194, 1983.

[3] W. H. Press, W. H., et al, Numerical Recipes: The Art of Scientific Computing, Cambridge University Press, New York, 2007.

[4] F. Riesz, F., Oeuvres complètes, 2 vol, Paris, Gauthier-Villars, 1960.

[5] J. V. Grabiner, J. V., The Changing Concept of Change: the derivative from Fermat to Weistrass, Mathematics magazine, vol 56, no. 14, pp 195-206, 1983.

[6] Rudin, Walter., Functional Analysis, Mc Graw-Hill, NY, 1991.

[7] Boyer, C. B., The History of Calculus and Its Conceptual Development, Dover, N Y, 1949.

[8] Henry, D. B., Differential Calculus in Banach Spaces, Dan Henry's Manuscript, http//www.ime.usp.br/map/dhenry/danhenry/math.htm, 2006

[9] Kato, T., Pertubation Theory for Linear Operators, Springer-Verlag, N Y, 1986.

[10] Bordr, K. C. and Aliprantes C. D., Infinite Dimension Real Analysis, Springer-Verlag, N Y, 2006. 